\title{
Spatial and Temporal Variability of Sea Surface Temperature in Eastern Marginal Seas of China
}

\author{
Renhao Wu, ${ }^{1,2,3}$ Jianmin Lin, ${ }^{3}$ and $\mathrm{Bo}^{\mathrm{Li}^{3}}$ \\ ${ }^{1}$ School of Marine \& Atmospheric Science, Ocean University of China, Qingdao 266100, China \\ ${ }^{2}$ State Key Laboratory of Satellite Ocean Environment Dynamics, Second Institute of Oceanography, State Oceanic Administration, \\ Zhejiang 310012, China \\ ${ }^{3}$ Marine Science and Technology College, Zhejiang Ocean University, Zhejiang 316022, China
}

Correspondence should be addressed to Renhao Wu; mikewu@zjou.edu.cn and Jianmin Lin; jmlin007@zjou.edu.cn

Received 25 November 2015; Revised 9 January 2016; Accepted 22 May 2016

Academic Editor: Jorge E. Gonzalez

Copyright ( 2016 Renhao Wu et al. This is an open access article distributed under the Creative Commons Attribution License, which permits unrestricted use, distribution, and reproduction in any medium, provided the original work is properly cited.

Spatial mean value evolution, long-term mean pattern, and seasonal as well as interannual variability of sea surface temperature (SST) in Eastern Marginal Seas of China (EMSC) are reanalyzed based on thirty years' NOAA optimum interpolation (OI) 1/4 degrees' daily SST data. Temporal evolution of the spatial mean value shows a very marked annual cycle and a weak warming tendency $\left(0.03437^{\circ} \mathrm{C} /\right.$ year $)$. Spatial distribution of the long-term mean value shows some more fine spatial structure of SST compared to previous studies. Over $90 \%$ of the temporal variability can be explained by the annual harmonic whose amplitude is one order larger than that of the semiannual harmonic. In addition, the annual harmonic amplitude distribution is consistent with that of the value of standard deviation. In order to investigate the interannual variation of SST, the EMSC SST interannual index was constructed. Based on wavelet analysis, a significant peak around 3.3 years was found in the EMSC SST interannual index. Further analysis demonstrated that the interannual variability of SST is linked with El Niño-Southern Oscillation (ENSO) teleconnection, through which anomalous surface heat flux warms or cools the EMSC during El Niño or La Niña events.

\section{Introduction}

The Eastern Marginal Seas of China (EMSC), consisting of the Bohai, Yellow, and East China Seas (Figure 1), surrounded by China mainland and the Korean Peninsula, are of the most important marginal seas in the Western North Pacific Ocean (WNPO). The EMSC connect to the Japan Sea through the Korea Strait, to the South China Sea through the Taiwan Strait, and to the Western Pacific Ocean in the southeast by the Okinawa Trough. As one of the most important oceanic variables, SST plays a crucial role in studying ocean dynamic, biogeochemical, and physical processes in the upper ocean. In addition, SST is a key factor to kinds of marine exploitation activities like aquaculture and swimming resort. Therefore, it is of theoretical and practical significance to get a thorough understanding of spatial and temporal variability of SST in the EMSC.

Extensive studies have been carried out on the SST variability of diverse timescales in the EMSC including daily [1], intraseasonal (20 90 days) [2], seasonal [3-8], interannual (2-7 years) [8-12], decadal (10 20 years), and long-term variations $[13-20]$. According to previous studies, the dominant factors controlling the SST variability may vary with the timescales of variations. Specifically, the high-frequency variations are usually associated with local forcing, such as tides and solar radiation [1]; the seasonal variations are dominated by many intricate factors, including the monsoon, oceanic advection, vertical mixing, and bathymetry [3-8]. However, the low-frequency variations are closely linked with large-scale air-sea interaction like ENSO and Pacific decadal oscillation as well as changes in Kuroshio and surface heat fluxes [9-20].

The studies mentioned above greatly improved our understanding of the variability of SST in the EMSC. However, most previous studies are based on either sparse in situ observational data $[1,7,8]$ or only short-term satellite remote sensing data $[2,5,6,11,14]$ or horizontal lowresolution reconstructed data $[15-17,20]$. It is well known that 


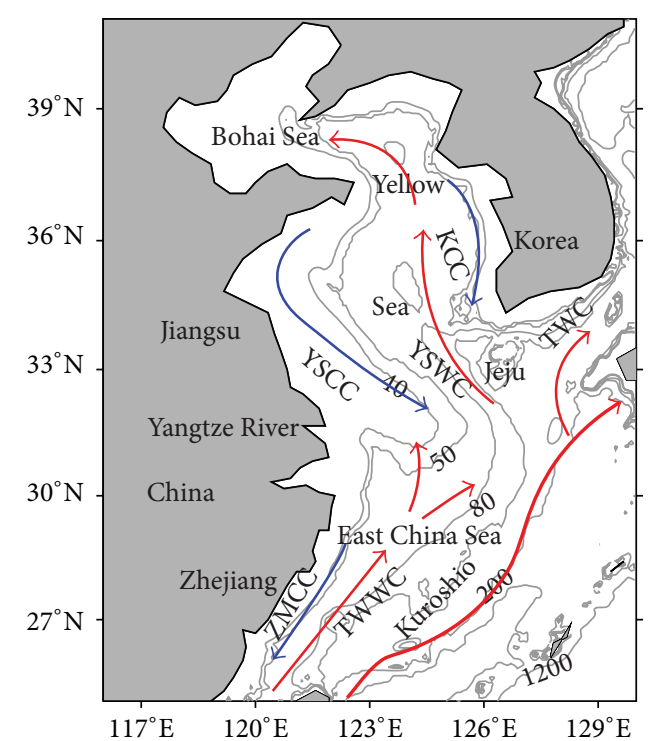

FIGURE 1: Schematic map of winter circulation in the Yellow Sea and East China Sea. The red arrows denote the warm currents and the blue arrows denote the cold currents. Gray lines are the bathymetry with 50, 80, 200, and $1200 \mathrm{~m}$ labeled. The warm currents include the Yellow Sea Warm Current (YSWC), the Taiwan Warm Current (TWWC), the Tsushima Warm Current (TWC), and Kuroshio. The cold currents include the Zheming Coastal Current (ZMCC), the Yellow Sea Coastal Current (YSCC), and Korea Coastal Current (KCC). This figure is based on [26, Figure 1].

in situ observations are poor in both temporal and spatial resolutions, while satellites remote sensing cannot observe SST with cloud on top of the ocean. Hence, the fine spatial structure and seasonal as well as interannual variations of SST in the EMSC and associated physical mechanisms need to be further studied by utilizing higher spatial resolution and longer time record datasets. In particular, the interannual variations of SST and its relationship with ENSO should be reexamined, although some studies $[12,14]$ pointed out that there might exist a close relationship between them but how ENSO exerts its influences on remote SST in the EMSC is still poorly understood.

In this paper, we applied the reanalyzed optimum interpolation SST (hereafter, OISST) data, to analyze both temporal and spatial variations of SST in the EMSC. Our results differ from previous studies $[1,6,8]$ and others in that a fine spatial structure of long-term mean value not seen in the coarse resolution data and detailed semiannual and annual variations of SST will be demonstrated and from studies $[12,14]$ in that a specific relationship between ENSO and the interannual variations of SST in the EMSC will be given. The paper is organized as follows. Data and methods are given in Section 2. Section 3 presents the results. Section 4 provides discussion and summary of our results.

\section{Data and Methodology}

The OISST [21] applied in this paper is reanalysis data based on shipboard, buoy, and satellite SST measurement.
The daily OISST data cover the world ocean with a horizontal resolution of $25 \mathrm{~km}$, which could be obtained from $\mathrm{ftp}: / /$ eclipse.ncdc.noaa.gov/pub/OI-daily-v2/. Then the SST data of the EMSC are extracted in the region of $117^{\circ} \mathrm{E} \sim 130^{\circ} \mathrm{E}$, $24^{\circ} \mathrm{N} \sim 42^{\circ} \mathrm{N}, 2264$ data points in total (Figure 1). The daily data from 1982 to 2011 are applied in this study. As we focus on the semiannual, annual, and interannual variations, we obtain the monthly averaged SST based on the daily dataset for further studies. In order to assess the contribution of surface heat fluxes to the variations of SST, surface heat fluxes including sensible and latent heat flux, long- and shortwave radiation data, air specific humidity, and wind speed datasets are provided by NCEP-CFSR [22] which uses the NCEP Coupled Forecast System Model. Heat fluxes datasets are interpolated onto the OISST data grid for consistency. In addition, all the above datasets have been weighted by cosine of latitudes before further analysis.

The mean values as well as the annual and semiannual harmonics for each station are calculated using a leastsquares method as

$$
\begin{aligned}
\mathrm{SST}_{\text {season }}= & \mathrm{SST}_{0}+\mathrm{SST}_{\mathrm{a}} \cos \left(\omega t-\varphi_{\mathrm{a}}\right) \\
& +\mathrm{SST}_{\mathrm{s}} \cos \left(2 \omega t-\varphi_{\mathrm{s}}\right),
\end{aligned}
$$

where $\mathrm{SST}_{\mathrm{a}}$ and $\mathrm{SST}_{\mathrm{s}}$ are the amplitude of annual and semiannual signal, respectively, $\mathrm{SST}_{0}$ is the time averaged mean value, $\omega=2 \pi / 12$ is the frequency of annual cycle, $\varphi_{\mathrm{a}}$ and $\varphi_{\mathrm{s}}$ are the phase of annual and semiannual signal, and $t$ is time.

\section{Results}

3.1. Spatial Mean Value. The spatial mean value of SST over the entire EMSC shows a well-defined annual cycle (Figure 2(a)) and certain interannual variability as well as a weak warming trend of $0.03437^{\circ} \mathrm{C}$ per year $(95 \%$ significant level). In Figure 2(b), the spatial mean value of surface net heat flux averaged over the whole domain also shows a similar feature but with a decreasing trend of $-0.48942 \mathrm{~W} \mathrm{~m}^{-2}$ per year (95\% significant level). The correlation between these two detrended time series reaches a maximum of 0.967 (>99\% significant level) with SST, a lag of two months. Therefore, we conclude that the notable annual cycle of SST is mainly driven by surface net heat flux. It should be noted that latent heat flux, the largest heat loss term during boreal winter over the EMSC, dominates sea surface heat budget and also shows a decreasing trend of $-0.433 \mathrm{~W} \mathrm{~m}^{-2}$ per year (>99\% significant level) (not shown here). The space standard deviations are small in summer and large in winter, which is opposite to the time series of spatial mean values. It means that the spatial distributions of both the SST and surface net heat flux are more homogeneous during boreal summer than that during boreal winter.

The anomaly value used here is defined as the deviation from the climatological annual cycle calculated over the entire period in each dataset. Time series of the spatial mean value of SST anomalies (SSTA) constructed over the whole EMSC (Figure 2(c) or Figure 4(a)) shows a distinct 


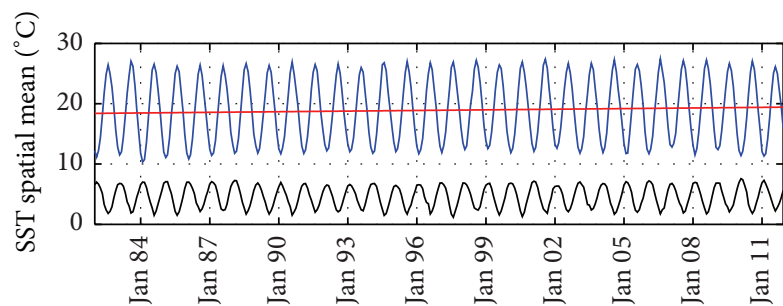

(a) Linear trend: $y=0.03437 * t+18.3929$

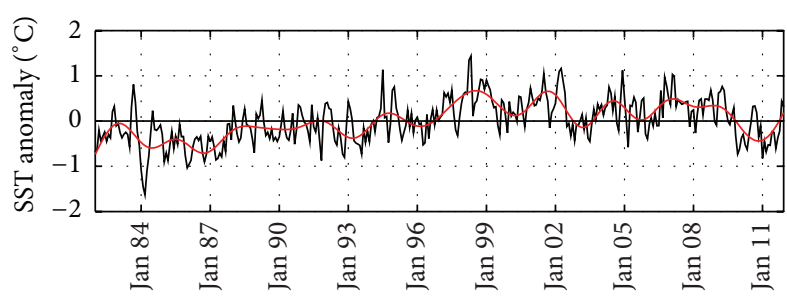

(c)

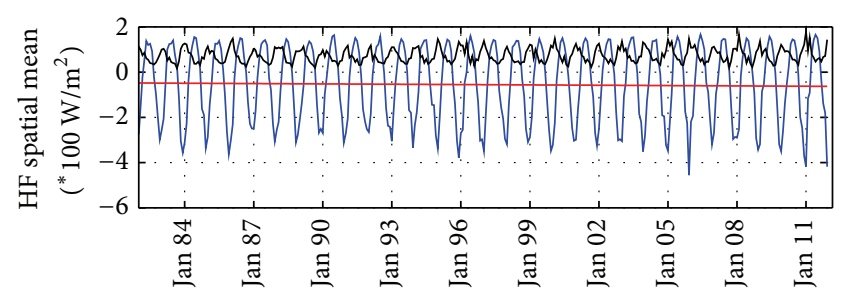

(b) Linear trend: $y=-0.48942 * t-48.0492$

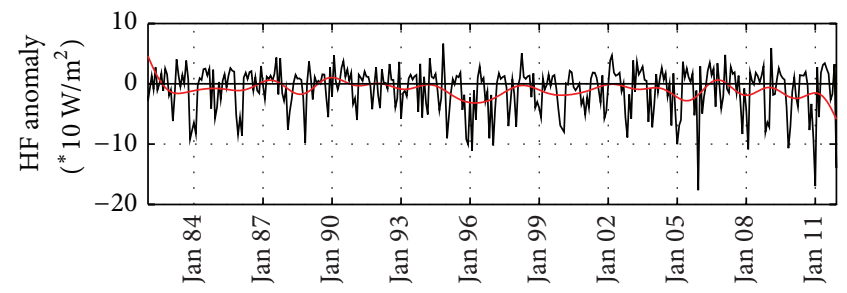

(d)

Figure 2: Temporal evolution of the spatial average of the monthly values (blue line) and long period tendency (red line) and its corresponding standard deviation (black line) for SST (a) and the surface net heat flux (b). Monthly mean values of the spatial anomaly with respect to the climatological annual cycle (black line) and series with low-pass-filter (>2 years) (red line) for SST (c) and the net surface heat flux (d).

interannual variability with remarkable fall and rise repeating several times. The maximum value of SSTA appeared in 1998. The trend lines (see blue lines in Figure 4(a)) might imply decadal-to-multidecadal variations in the SSTA time series, with a warming epoch during 1982-1998 and a cooling tendency from 1999 to 2011. The decadal warming or cooling observed in the EMSC will be detailedly examined in the future studies. Here, we only focus on the interannual variations and unravel the underlying mechanisms in Section 3.4. The spatial mean value of surface net heat flux anomaly (Figure 2(d)) shows a similar evolution to that of SSTA but without notable rising or decreasing trend. We will further discuss the relationship between them in Section 3.4.

3.2. Temporal Mean Value. Figure 3(a) presents the spatial distribution of temporal mean value of SST averaged over the period from 1982 to 2011. It is worth mentioning that the spatial patterns of long-term mean value are quite similar to that of mean value only during boreal winter [6, Figure 1] with the exception of magnitude, which suggests that the spatial pattern of the long-term mean value is determined by SST values during winter. Apart from direct solar radiation flux, such a pattern might be governed by the oceanic currents system in this region. For instance, the large values were observed over the path of the Taiwan Warm Current (TWWC) and Kuroshio and extended southeastward toward open waters with diagonally slanted isolines aligned southwest to northeast. These two warm currents transport warm water northeastward from low latitude (the schematic map of oceanic currents is shown in Figure 1). Owing to the Yellow Sea Warm Current (YSWC), a warm tongue was found in the Yellow Sea and extended northwestward from Jeju Island. Two cold tongues were observed on the west and east side of the YSWC, probably created by the Yellow Sea Coastal Current (YSCC) and Korean Coastal Current (KCC), respectively. However, a close examination of the relationship between bathymetry features (Figure 1) and long-term mean value patterns (Figure 3(a)) in this region reveals a different story in which large values are located roughly in the deeper parts of the domain (such as in the channel) while small values are observed in the shallow coastal region, which implies that bottom topography may play an important role in creating such a pattern of the long-term mean value of SST in the EMSC [6]. Detailed exploration of the physical mechanisms controlling the spatial distribution of the longterm mean value of SST is beyond the scope of this study.

The standard deviation of SST calculated based on the entire period (Figure 3(b)) shows an opposite pattern to that of temporal mean value (Figure 3(a)), with large values found over the shallow and high latitude regions and small values observed over the warm current path regions or deep parts of the study domain. In particular, the smallest value was found over parts of the Kuroshio path. Since the standard deviation was calculated based on the time series of SST containing the strong seasonal cycle signal at each station, the spatial structure of standard deviation is quite similar to that of the amplitude of annual cycle (Figure 3(c)), demonstrating that, at each station, most of the temporal variability can be attributed to the annual cycle.

3.3. Annual Cycle. We calculated the annual and semiannual harmonics of SST variations for each station in the EMSC according to (1). Nearly coinciding with the spatial distribution of standard deviation shown in Figure 3(b), large values of the amplitude of annual harmonic component were also found in shallow regions of our study domain, with a maximum value $\left(\sim 9^{\circ} \mathrm{C}\right)$ detected at the very shallow coastal zones. In contrast, small values were observed in the deep parts of the domain. Xie et al. (2002) [6] proposed one possible mechanism to explain why the spatial structure of the amplitude of annual harmonics displays such a pattern. The bottom topography of EMSC is characterized by 


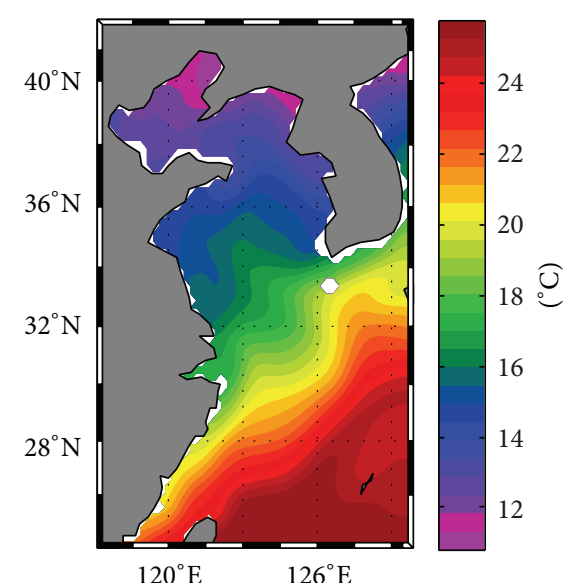

(a) Temporal mean

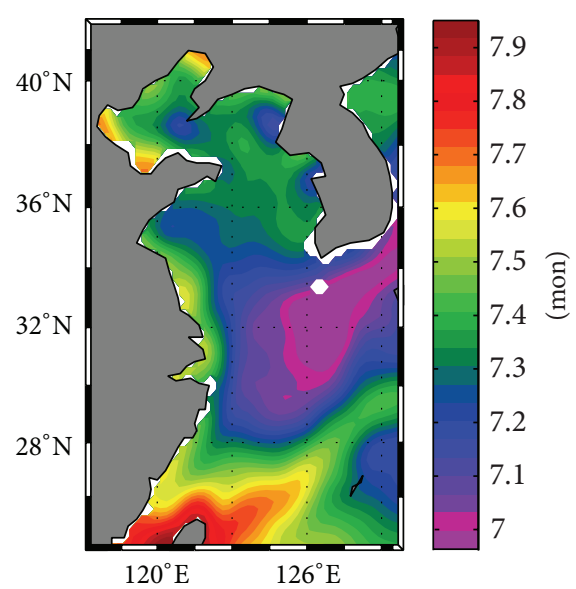

(d) Phase (annual)

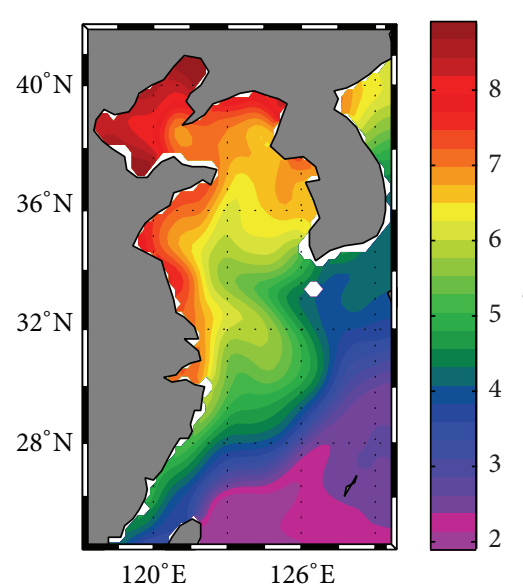

(b) Standard deviation

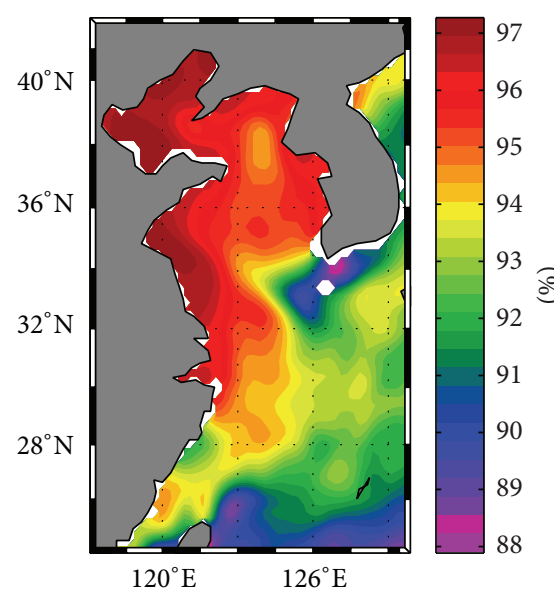

(e) Explained variance (annual)

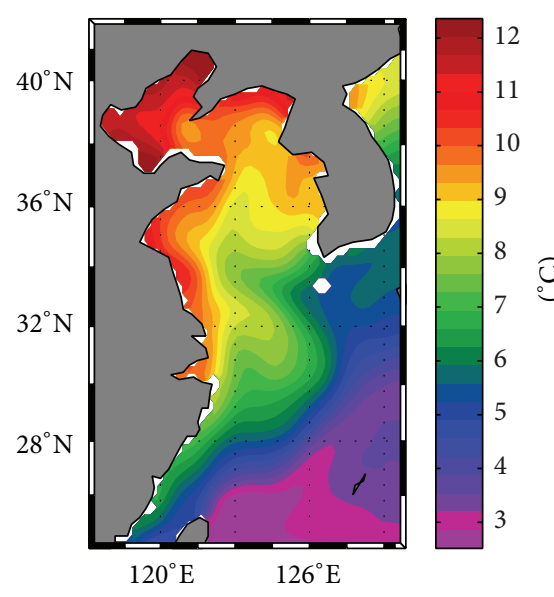

(c) Amplitude (annual)

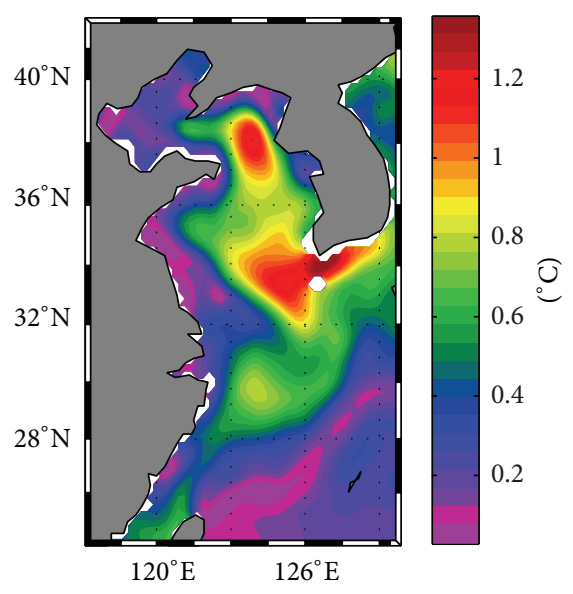

(f) Amplitude (semiannual)

FIGURE 3: Spatial distribution of the temporal mean SST (a) and its corresponding standard deviation (b). Spatial distribution of the amplitude (c) and the phase (month) (d) and the percentage of explained variance for the annual harmonic (e). Spatial distribution of the amplitude (d) for the semiannual harmonic.

shallower and deeper tonguelike regions with depth at a range from a few meters to a little more than $100 \mathrm{~m}$ (Figure 1). During boreal winter, the cold Eastern Asian winter monsoon winds blow over the EMSC, cooling their surface, inducing intense vertical mixing, and thereby a bottom-up heat transfer occurred. Because of the deeper zones containing more heat, it has a slower cooling rate than that of the shallower regions so that the water depth determines the cooling rate. This mechanism may work together with the advection of warm currents such as TWWC and YSWC. A quantitative assessment of the roles of bottom topography and warm currents has yet to be made. Meanwhile during summer, SST is nearly characterized by a spatial uniform pattern in the EMSC (not shown). Therefore, a stronger annual cycle is found over the shallow regions.

The spatial structure of the phase (months) of the annual harmonic component which indicates the moment of the year having the maximum SST value is shown in Figure 3(d). SST reaches the highest value in most of the study domain around July. There is a region in the south of Korean $\left(123 \sim 129^{\circ} \mathrm{E}, 30 \sim\right.$ $34^{\circ} \mathrm{N}$ ) reaching the highest SST as early as the beginning of
July, while the regions around the Taiwan Island approach the highest SST finally, nearly by the end of July.

Over $90 \%$ of the total SST variability can be explained by annual harmonic component in the whole Bohai Sea, most of the Yellow Sea, and the coastal region of East China Sea (these zones are generally shallow in the EMSC) (Figure 3(e)), which suggests that variations of SST in these regions are dominated by annual cycle. The small values of the explained variance for annual harmonic are located in the Kuroshio path as well as around Jeju Island regions. Regarding the Jeju Island regions, the small values might be associated with the relative strong semiannual variations (Figure 3(f)).

The amplitudes of the semiannual harmonic are one order smaller than those of the annual harmonic (Figure 3(f)). The largest amplitude of semiannual harmonic is located around Jeju Island. The amplitude of both semiannual and annual harmonic is small in the Kuroshio path regions compared to the remaining parts of the EMSC, which implies that the interannual or decadal variations might be strong in these zones. The annual harmonic indicates six months of heating and six months of cooling. However, with the semiannual 


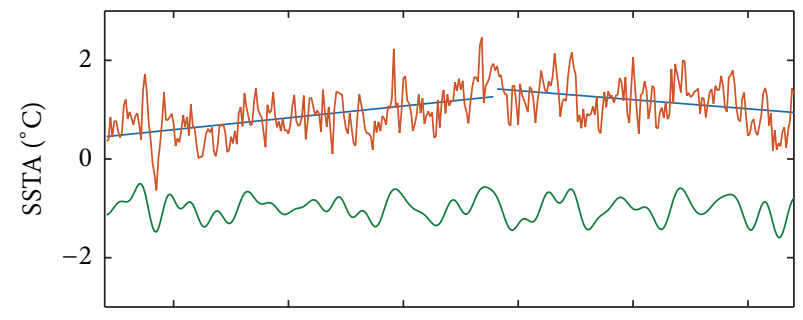

(a) EMSC SSTA index

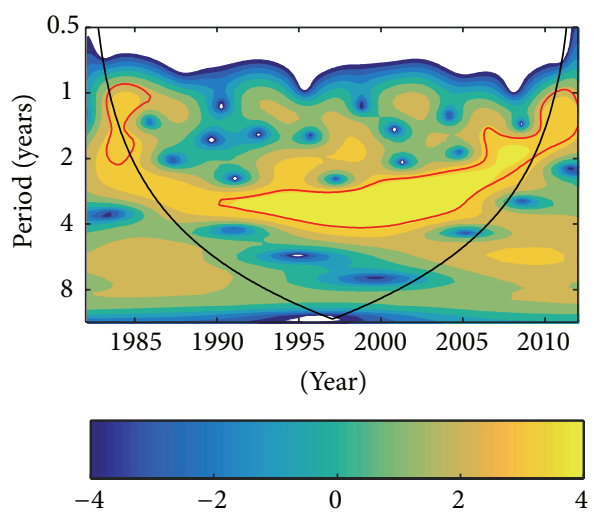

(b) Wavelet power spectrum

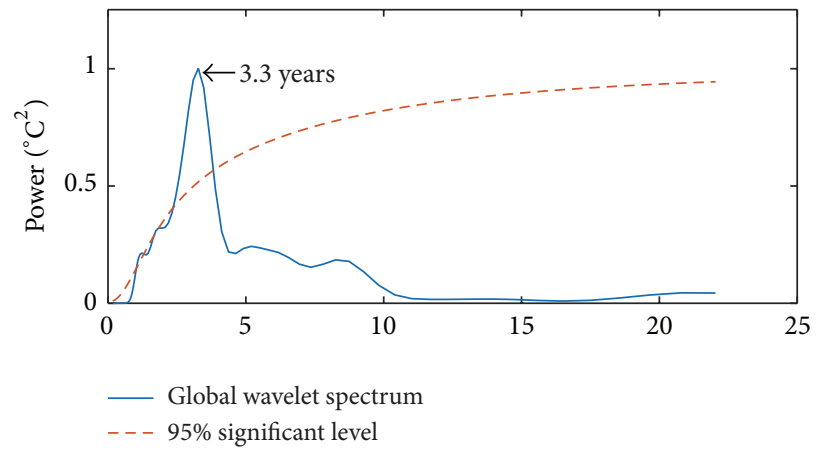

(c) Global wavelet spectrum

FIGURE 4: (a) Green curve represents the EMSC SST interannual index constructed by spatial mean SSTA (red curve line) subtracting the warming and cooling trend (blue straight line) and then filtering out signals with period $<1$ year and $>8$ years. (b) Continuous wavelet power spectrum for EMSC SST interannual index. Shading corresponds to log2(power). The red contour designates the 5\% significance level against red noise and the black line indicates the cone of influence (for detailed technique see Torrence and Compo, 1998 [23]; MATLAB code can be obtained from http://paos.colorado.edu/research/wavelets/). (c) Global wavelet spectrum for EMSC SST interannual index.

harmonic taken into account, this symmetry gets broken. In the regions where the amplitudes of the semiannual harmonic are higher, the heating periods are shortened, which helps explain why the SST of Jeju Island region first reaches its peak (Figure 3(d)).

3.4. Interannual Variations. In order to understand the interannual variability of SST in the EMSC, we first obtained time series of the spatial mean value of SSTA from which the annual and semiannual cycle of the initial SST time series at each station have been subtracted. As shown in Figure 4(a) (red curve line), this SSTA time series clearly presents a decadal warming trend at a rate $0.049^{\circ} \mathrm{C}$ per year $(>99 \%$ significant level) during $1982-1998$ and cooling trend at a rate around $-0.037^{\circ} \mathrm{C}$ per year $(90 \%$ significant level) during 1999-2011 (see the blue trend line which was acquired by least-squares method). As to the observed decadal warming and cooling trend, we will discuss it specially in another paper. Here, we again just subtract the warming and cooling trend from the obtained time series and further filtered out signals with period $<1$ year and $>8$ years to highlight interannual variations. We defined this resultant time series as the EMSC SST interannual variations index (shown in Figure 4(a), green curve line, hereafter, EMSC SST index).
To reveal the significant period of the interannual variability, the EMSC SST index is analyzed with the wavelet transform. The Morlet wavelet is adopted, and the transform is performed in Fourier space (see Torrence and Compo, 1998 [23], for detailed description). As shown in Figures 4(b) and $4(\mathrm{c})$, there is clearly significant peak with $\sim 3.3$ years and high power in the 2-4-year band after 1990, which share a common feature with that of ENSO index (here using NINO3 SSTA index obtained from http://www.cpc.ncep .noaa.gov/data/indices/ersst4.nino.mth.81-10.ascii) and that of heat flux index defined as the time series of spatial mean value for the surface net heat fluxes anomaly (not shown). The NINO3 SSTA index and heat flux index have been handled with the same method as the EMSC SST index before further analysis. Hence, it is expected that the interannual variations might be driven by ENSO teleconnection through which anomalous surface heat fluxes probably warm or cool the SST in the EMSC during El Niño or La Niña events.

To test the hypothesis mentioned above, a lead or lag correlation among the EMSC SST index, heat flux index, and NINO3 SSTA index is analyzed. As shown in Figure 5, the correlation reaches a maximum $\sim 0.57$ (above the $99 \%$ significant level) between EMSC SST index and heat flux index with the former lag of 3 months. On the other hand, the 


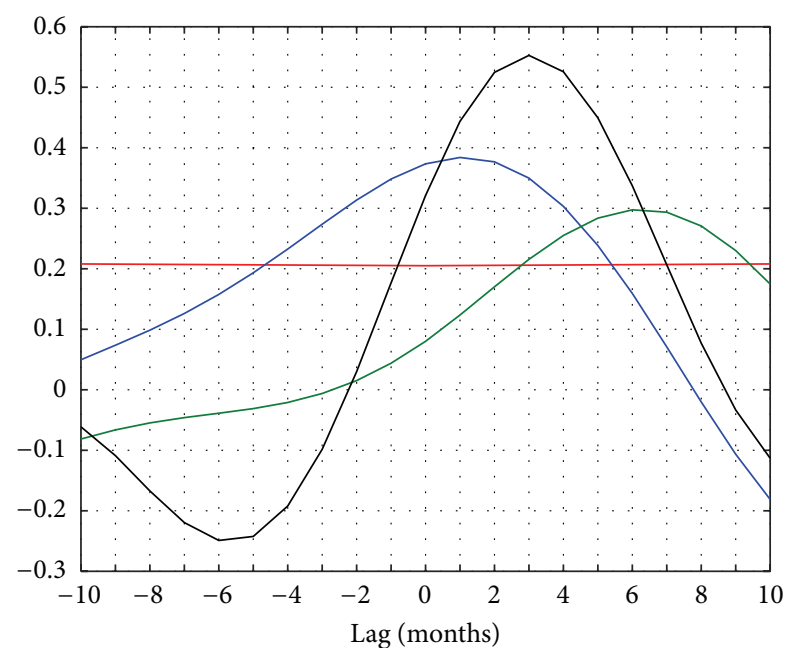

- > $>99 \%$ significant level

_ Corr (heat flux, NINO3) with NINO3 lead (lag $>0$ )

_ Corr (SST index, NINO3) with NINO3 lead (lag >0)

— Corr (SST index, heat flux) with heat flux lead (lag $>0$ )

FIGURE 5: Lead and lag correlation between detrended spatial mean value of sea surface net heat flux anomaly and NINO3 SSTA index obtained from http://www.cpc.ncep.noaa.gov/data/indices/ ersst4.nino.mth.81-10.ascii (blue line; lag $>0$ means NINO3 lead), between EMSC SST interannual index and detrended spatial mean value of sea surface net heat flux anomaly (black line; lag $>0$ means heat flux lead), and between EMSC SST interannual index and NINO3 SSTA index (green line; lag > 0 means NINO3 lead).

heat flux index shows a significant correlation with NINO3 SSTA index around 0.39 (above the 99\% significant level) with the former lag of 1 month. As expected, the EMSC SST index displays a correlation with NINO3 SSTA index around 0.31 with the former lag of 6 months; this is consistent with the previous finding [12]. It should be noted that the correlation between NINO3 SSTA index and EMSC SST index is modest although significant. Furthermore, it seems paradoxical that lag of 6 months between them is not equal to a lag of 3 months between EMSC SST index and heat flux index plus a lag of 1 month between heat flux index and NINO3 SSTA index. However, the patterns of global SST anomaly regression onto the standardized EMSC SST index with the latter lag of 6 months depict a definite canonic El Niño structure (shown in Figure 7). In addition, a simple linear correlation might not account for the total relationship among them; other factors like nonlinear effects may play a part.

To clarify how ENSO exerts its influence on the EMSC, each of the heat flux terms is regressed onto the NINO3 SSTA index with the former lag of 1 month (indeed a lag of 2 or 3 months makes no significant differences). During El Niño, especially in its peak time (normally in December), an anomalous anticyclone often forms over the subtropical northwest Pacific [24] and thereby weakens the Asian winter monsoon (Figure 6(f)) and exhibits southeasterly anomalies over most regions of the EMSC which brings moisture from the tropical ocean and reduces air-sea specific humidity difference (Figure 6(h)) and in turn decreases the latent heat loss (Figure 6(b)). In the meantime, the weakened winter monsoon gives rise to positive sensible heat flux anomalies (Figure 6(a)) with a quite similar spatial structure to that of wind speed anomalies (Figure 6(f)). Meanwhile, the radiation heat fluxes present opposite influences over the shelf seas (Figures 6(c) and 6(d)). On the shelf seas, due to an increased cloud cover (Figure $6(\mathrm{~g})$ ), the shortwave radiation flux decreases (Figure 6(d)). Nevertheless, the enhanced latent heat gain dominates the ocean surface heat fluxes budget. As a result, the net positive surface heat flux (Figure 6(e)) warms most areas of the EMSC during El Niño. As one of the most significant interannual variations of the Earth's climate system, ENSO varies between anomalously warm (El Niño) and cold (La Niña) conditions. Hence, it is expected that negative anomalous surface heat flux might induce cooling in the EMSC during La Niña.

\section{Discussion and Summary}

In this study, we examined the spatial mean value evolution and spatial distribution of long-term mean value and seasonal as well as interannual variations of SST in the EMSC based on the 30-year OISST data from 1982 to 2011. Temporal evolution of the spatial mean value shows a very marked annual cycle and a weak warming trend $\left(0.03437^{\circ} \mathrm{C} /\right.$ year $)$. A high correlation between the detrended time series of spatial mean value of SST and surface net heat fluxes indicates that the annual cycle of SST is dominated by net surface heat flux. The spatial mean value of surface net heat flux averaged over the whole EMSC displays a decreasing trend.

Spatial structure of the long-term mean value of SST is characterized by large values located in the deep parts of the EMSC while small values are generally found in the shallow waters. Such a pattern might be linked to the special bottom topography [6] as well as the oceanic currents system in the EMSC. A 3D numerical model is needed to evaluate the influence of each potential factor on creating the patterns of long-term mean of SST in the future study. It should be noted that, due to the SST dataset with higher spatial resolution used in this study, our results show some finer spatial structure of SST, such as the warm and cold tongue patterns locations and their extensions compared to previous studies $[6,15]$ and so forth.

Spatial distribution of standard deviation, annual harmonic amplitude, and explained variance of annual harmonic all together reveal that the strong annual cycle dominates the total SST variability over the shallow zones in the EMSC. Semiannual harmonic variation is one order smaller than that of annual harmonic with high values found around Jeju Island region. The phase of the annual harmonic demonstrates that the moment of the year with maximum SST in most regions of our study domain is between July 1 and August 1 .

In order to investigate the interannual variations of SST, the EMSC SST interannual index was constructed. Based on wavelet analysis, a significant peak around 3.3 years was found in the EMSC SST interannual index. Further analysis demonstrated that the interannual variability of SST is intimately linked with ENSO teleconnection, through which anomalous surface heat flux warms or cools the EMSC. 


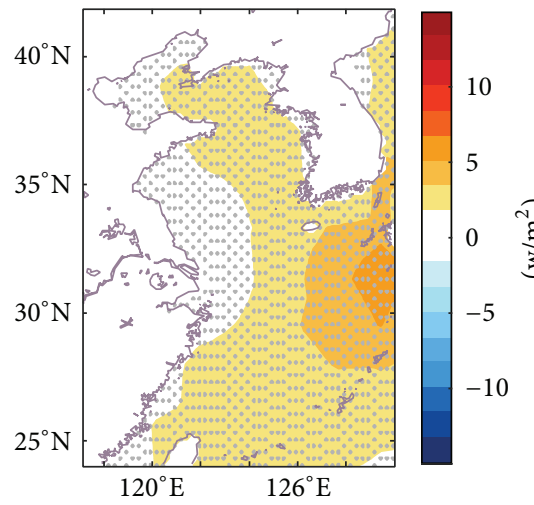

(a) $\mathrm{sh}$

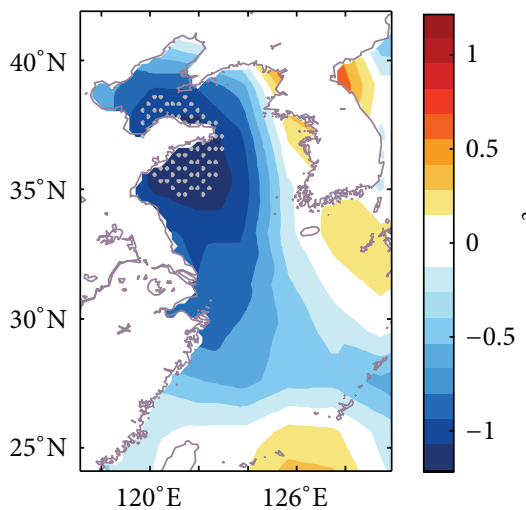

(d) $\mathrm{sw}$

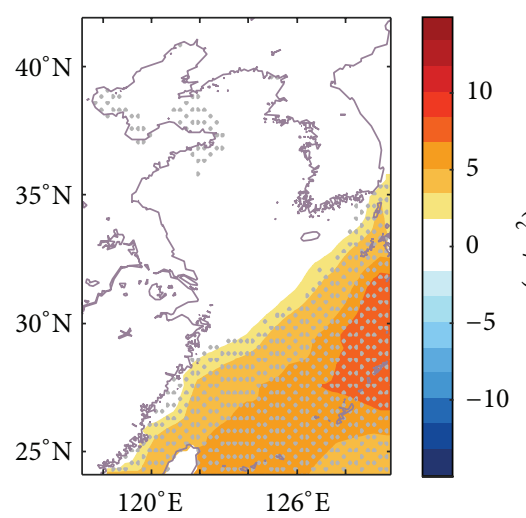

(b) $\mathrm{lh}$

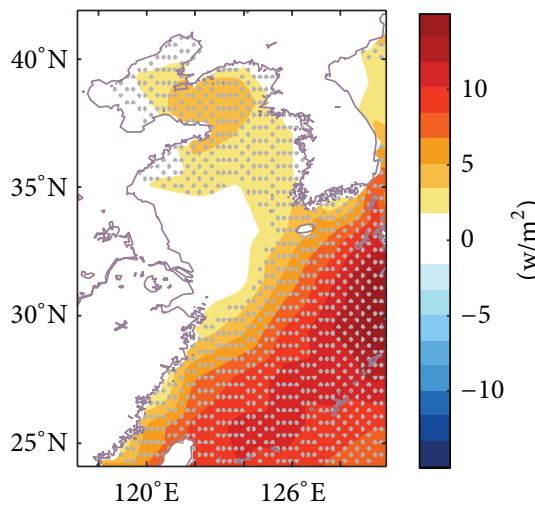

(e) qnet

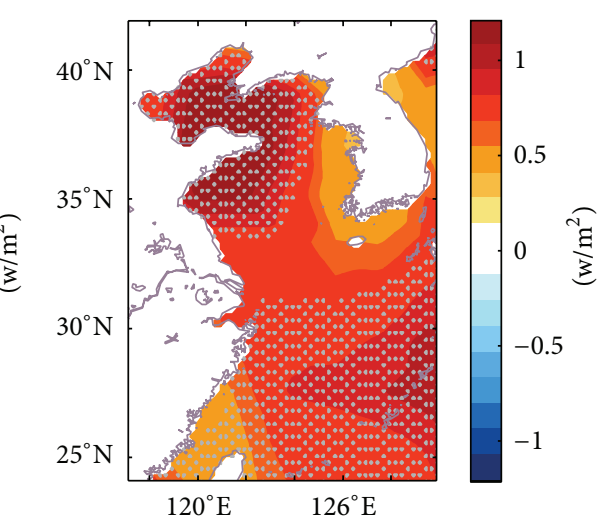

(c) $\mathrm{lw}$

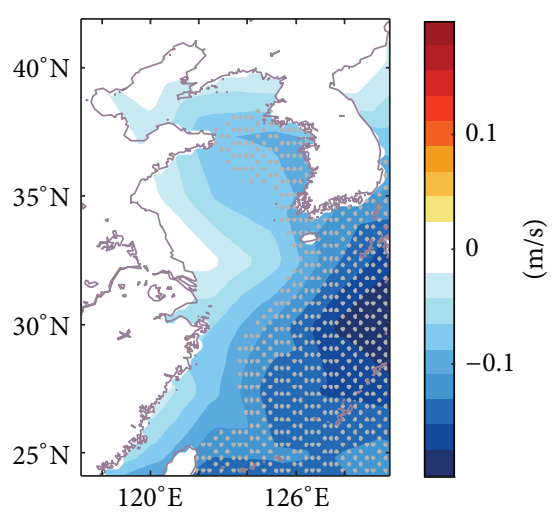

(f) $\mathrm{U}$

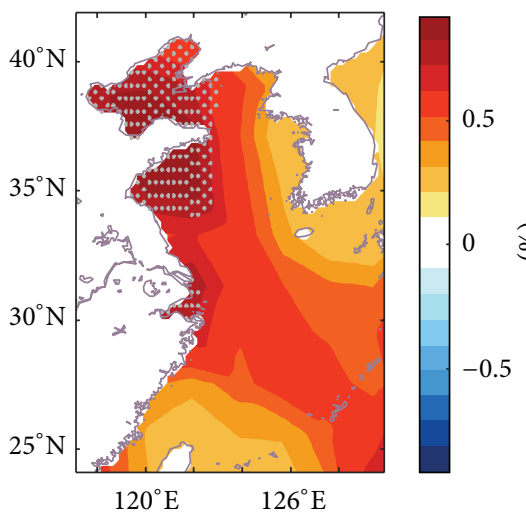

(g) Cloud

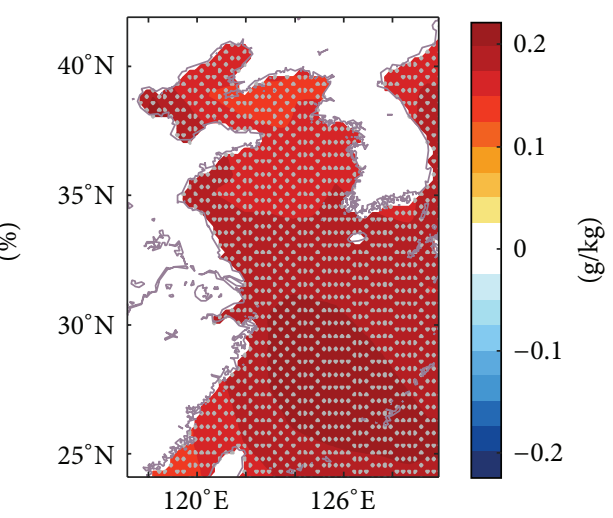

(h) $\mathrm{dq}$

FIGURE 6: Regression maps of surface heat flux terms (positive downward), including (a) sensible heat flux, (b) latent heat flux, (c) long-wave radiation, (d) short-wave radiation, (e) net heat flux, (f) wind speed, (g) total cloud cover, and (h) specific humidity difference at $10 \mathrm{~m}$ against a lead of 1 month of the standardized NINO3 SSTA index. The gray spots denote 95\% confidence level using Student's $t$-test.

Although we claimed that ENSO plays an important role in the interannual variations of SST in the EMSC, our analysis is qualitative rather than quantitative and a simple linear correlation or regression analysis cannot tell the whole story between them. In addition, other climate systems such as the East Asian monsoon or North Pacific Oscillation may play a part. Yeh and Kim, 2010 [17], pointed out that the long-term variations of SST during boreal winter are well explained by the North Pacific Oscillation. In contrast, Park et al., 2012 [25], showed that winter SST anomalies over the
East Asian marginal seas are significantly correlated with the East Asian winter monsoon. There might exist a complicated relationship among ENSO, North Pacific Oscillation, and East Asian winter monsoon which needs to be examined in future studies.

It is worth mentioning that the decadal warming observed in the EMSC (shown in Figure 4(a)) is not limited to the EMSC. As shown in Figure 8, most regions of WNPO including Japan Sea and Kuroshio and its extension zones show in synchrony with the rapid warming in EMSC during 


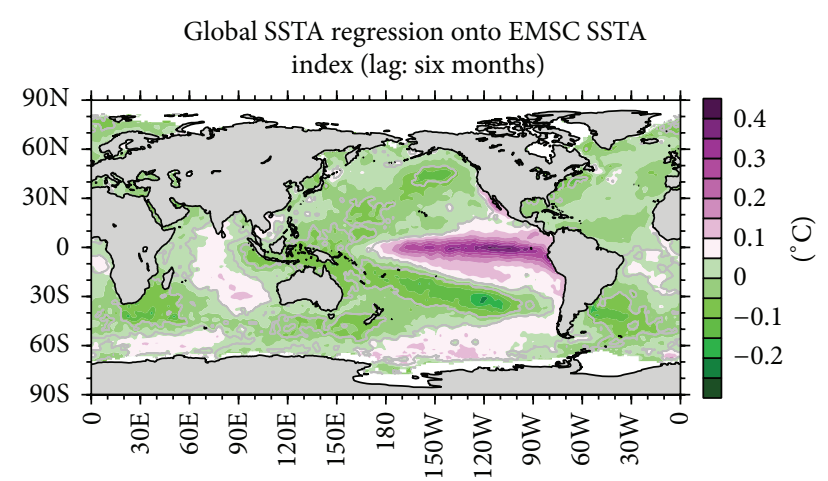

FIGURE 7: Global SSTA during 1982-2011 regression onto a lag of six months of standardized EMSC SST interannual index. The gray contours denote 95\% confidence level using Student's $t$-test.

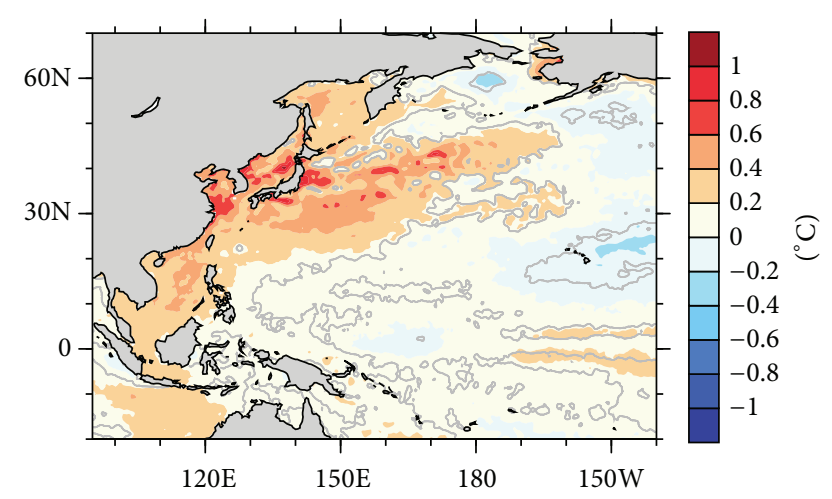

Figure 8: Northwestern Pacific SSTA during 1982-1998 regression onto the time series of standardized EMSC SSTA averaged over the whole EMSC. The gray contours denote $95 \%$ confidence level using Student's $t$-test.

1982-1998. Recently, Wu et al., 2012 [27], found an enhanced warming from 1900 that occurred over WNPO subtropical boundary currents regions based on two solely historical observational pieces of data (HadSST2, Minobe/Maeda SST) and four reanalyzed pieces of data (HadISST1, SODA, ERSSTv3b, and Kaplanv2) (see [27] for detailed description of these SST datasets). There are similar accelerated warming signals in all of these SST datasets, implying that their result is robust. Indeed the patterns shown in Figure 8 is quite similar to their findings [27, Figure 1], although we focus on a much shorter period from 1982 to 1998, which might suggest that the decadal warming during 1982-1998 makes a great contribution to centennial warming over WNPO subtropical boundary currents regions. Many possible mechanisms have been proposed to explain the causes of WNPO warming but still under active debating: the enhanced warming over the EMSC is associated with the intensification of western boundary currents $[15,16,27]$, surface heat fluxes $[17,28]$, and stronger winter monsoon [18], while the interdecadal variability of Kuroshio extension SST is closely linked with the subsurface dynamic [29] and interdecadal variation of the Aleutian low activity [30]. It is strikingly shown in Figure 8 that the region near the Yangtze River mouth displays a much more significant warming compared to other regions of the EMSC. According to the findings of Park et al., 2011 [31], the Yangtze River discharge tends to intensify stratification and thereby reduces entrainment and vertical mixing at the mixed layer base, which might induce interdecadal warming of SST over the East China Sea. Therefore, it is very likely that the significant warming observed near the Yangtze River mouth is related to an intensification of Yangtze River discharge, which needs to be further investigated. In addition, based on our recent studies (submitted to Atmospheric Science Letters), the asymmetry in the ENSO teleconnection and the more frequent El Niño events within recent decades are also the possible factors inducing warming over the EMSC during 1982-1998. Furthermore, the more frequent El Niño events bring more rainfall [32] and thus induce Yangtze River valley floods which might increase SST near the Yangtze River mouth. The above hypothesis needs to be systematically tested based on coupled ocean-atmosphere model simulations.

\section{Competing Interests}

The authors declare that there are no competing interests regarding the publication of this paper.

\section{Acknowledgments}

This study is supported by the open fund (SOED1413) of the State Key Laboratory of Satellite Ocean Environment Dynamics (Second Institute of Oceanography, SOA), the Startup Foundation (21105013015) of Zhejiang Ocean University, Zhejiang Provincial Natural Science Foundation of China (no. LZ14D060001), and the Opening Foundation from Marine Sciences in the Most Important Subjects of Zhejiang (no. 20130113).

\section{References}

[1] X. C. Weng, Q. L. Zhang, Y. K. Zhang, and Y. L. Yang, "Characteristics of the daily variations of water temperature in the Bohai Sea, Yellow Sea and East China Sea," Marine Science, vol. 6, pp. 49-54, 1993 (Chinese).

[2] G. E. Zeng, S. M. Lian, X. H. Chen, Z. L. Hua, and Y. Q. Qi, "EOF analysis of intra-seasonal variabilities of SST in the East China Sea and Yellow Sea," Advances in Marine Science, vol. 24, no. 2, pp. 146-155, 2006 (Chinese).

[3] Q. Liu, S. P. Xie, L. Li, and N. A. Maximenko, "Ocean thermal advective effect on the annual range of sea surface temperature," Geophysical Research Letters, vol. 32, no. 24, Article ID L24604, 2005.

[4] H. H. Furey and A. S. Bower, "Synoptic temperature structure of the East China and southeastern Japan/East Seas," Deep-Sea Research Part II: Topical Studies in Oceanography, vol. 52, no. 11-13, pp. 1421-1442, 2005.

[5] X. W. Bao, X. Q. Wan, G. P. Gao, and D. X. Wu, "The characteristics of the seasonal variability of the sea surface temperature field in the Bohai Sea, the Huanghai Sea and the East China Sea from AVHRR data," Acta Oceanologica Sinica, vol. 24, no. 5, pp. 125-133, 2002 (Chinese). 
[6] S. P. Xie, J. Hafner, Y. Tanimoto, W. T. Liu, H. Tokinaga, and H. $\mathrm{Xu}$, "Bathymetric effect on the winter sea surface temperature and climate of the Yellow and East China Seas," Geophysical Research Letters, vol. 29, no. 24, pp. 81-1-81-4, 2002.

[7] M. Y. Tang, Y. Z. Liu, H. H. Li et al., "A preliminary analysis of the characteristics and formation causes of seasonal variability of averaged sea surface temperature field in the Bohai Sea, the Yellow Sea and the northern East China Sea," Acta Oceanologica Sinica, vol. 11, pp. 544-553, 1989 (Chinese).

[8] M. Y. Tang, J. Yin, R. M. Qu, and P. Sui, "Annual and interannual variations of SST of the East China Sea measured from islands influenced by Kuroshio water," Acta Oceanologica Sinica, vol. 16, no. 3, pp. 12-20, 1994 (Chinese).

[9] X. H. Tang, A Preliminary Study on the Interannual-to-Interdecadal Variability of Thermohaline Structures in the Northern East China Sea, Institute of Oceanology of Chinese Academy of Sciences, Qingdao, China, 2003, [Chinese].

[10] W.-S. Park and I. S. Oh, "Interannual and interdecadal variations of sea surface temperature in the East Asian marginal seas," Progress in Oceanography, vol. 47, no. 2-4, pp. 191-204, 2000.

[11] Y. F. Li, P. F. Guo, and G. Y. Li, "The EOF analysis of the sea surface temperature in the East China sea," Transactions of Oceanology and Limnology, no. 7, pp. 1-4, 2007 (Chinese).

[12] D. H. Song, H. M. Yu, and X. W. Bao, "Analysis of the interannual variability of the Eastern China seas and its adjacent seas surface temperature," Ocean University of China, vol. 37, supplement, pp. 21-28, 2007 (Chinese).

[13] Y. L. Chen and C. R. Ho, "A study on global and regional sea surface temperature trends," Journal of Photogrammetry and Remote Sensing, vol. 7, pp. 41-58, 2002.

[14] F. Yu and Y. Xu, "Study of long-term variational trend of sea surface temperature in the East China Sea," Chinese Advances in Marine Science, vol. 21, no. 4, pp. 477-481, 2003.

[15] L. Feng and X. P. Lin, "Long-term trend of the East China Sea surface temperature during 1945-2006," Periodical of Ocean University of China, vol. 39, pp. 13-18, 2009 (Chinese).

[16] L. Zhang, L. Wu, X. Lin, and D. Wu, "Modes and mechanisms of sea surface temperature low-frequency variations over the coastal China seas," Journal of Geophysical Research, vol. 115, no. 8, 2010.

[17] S.-W. Yeh and C.-H. Kim, "Recent warming in the Yellow/East China Sea during winter and the associated atmospheric circulation," Continental Shelf Research, vol. 30, no. 13, pp. 1428-1434, 2010.

[18] L.-Y. Oey, M.-C. Chang, Y.-L. Chang, Y.-C. Lin, and F.-H. Xu, "Decadal warming of coastal China Seas and coupling with winter monsoon and currents," Geophysical Research Letters, vol. 40, no. 23, pp. 6288-6292, 2013.

[19] Q. Y. Liu and Q. Zhang, "Mechanism of sea surface temperature sustained warming in the East China seas," Periodical of Ocean University of China, vol. 44, pp. 001-008, 2014 (Chinese).

[20] B. L. Bao and G. Y. Ren, "Climatological characteristics and long-term change of SST over the marginal seas of China," Continental Shelf Research, vol. 77, pp. 96-106, 2014.

[21] R. W. Reynolds, T. M. Smith, C. Liu, D. B. Chelton, K. S. Casey, and M. G. Schlax, "Daily high-resolution-blended analyses for sea surface temperature," Journal of Climate, vol. 20, no. 22, pp. 5473-5496, 2007.

[22] S. Saha, S. Moorthi, H.-L. Pan et al., "The NCEP climate forecast system reanalyses," Bulletin of the American Meteorological Society, vol. 91, pp. 1015-1057, 2010.
[23] C. Torrence and G. P. Compo, "A practical guide to wavelet analysis," Bulletin of the American Meteorological Society, vol. 79, no. 1, pp. 61-78, 1998 .

[24] B. Wang, R. Wu, and X. Fu, "Pacific-East Asian teleconnection: how does ENSO affect East Asian climate?" Journal of Climate, vol. 13, no. 9, pp. 1517-1536, 2000.

[25] Y.-H. Park, J.-H. Yoon, Y.-H. Youn, and F. Vivier, "Recent warming in the western North Pacific in relation to rapid changes in the atmospheric circulation of the Siberian high and Aleutian low systems," Journal of Climate, vol. 25, no. 10, pp. 3476-3493, 2012.

[26] C. Bian, W. Jiang, and R. J. Greatbatch, "An exploratory model study of sediment transport sources and deposits in the Bohai Sea, Yellow Sea, and East China Sea," Journal of Geophysical Research: Oceans, vol. 118, no. 11, pp. 5908-5923, 2013.

[27] L. Wu, W. Cai, L. Zhang et al., "Enhanced warming over the global subtropical western boundary currents," Nature Climate Change, vol. 2, no. 3, pp. 161-166, 2012.

[28] R. T. Sutton, B. Dong, and J. M. Gregory, "Land/sea warming ratio in response to climate change: IPCC AR4 model results and comparison with observations," Geophysical Research Letters, vol. 34, no. 2, Article ID L02701, 2007.

[29] B. Taguchi, S.-P. Xie, N. Schneider, M. Nonaka, H. Sasaki, and Y. Sasai, "Decadal variability of the Kuroshio Extension: observations and an eddy-resolving model hindcast," Journal of Climate, vol. 20, no. 11, pp. 2357-2377, 2007.

[30] S. Sugimoto and K. Hanawa, "Decadal and interdecadal variations of the Aleutian Low activity and their relation to upper oceanic variations over the North Pacific," Journal of the Meteorological Society of Japan, vol. 87, no. 4, pp. 601-614, 2009.

[31] T. Park, C. J. Jang, J. H. Jungclaus, H. Haak, W. Park, and I. Sang Oh, "Effects of the Changjiang river discharge on sea surface warming in the Yellow and East China Seas in summer," Continental Shelf Research, vol. 31, no. 1, pp. 15-22, 2011.

[32] T. Park, C. J. Jang, M. Kwon, H. N. Na, and K.-Y. Kim, "An effect of ENSO on summer surface salinity in the Yellow and East China seas," Journal of Marine Systems, vol. 141, pp. 122127, 2015. 

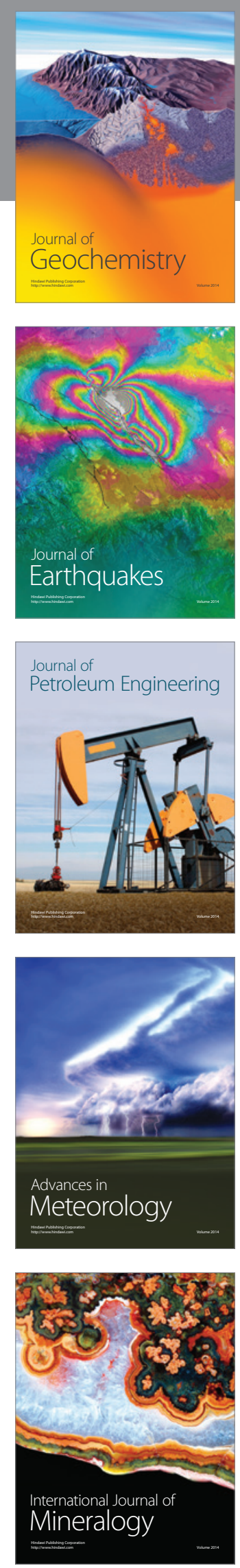
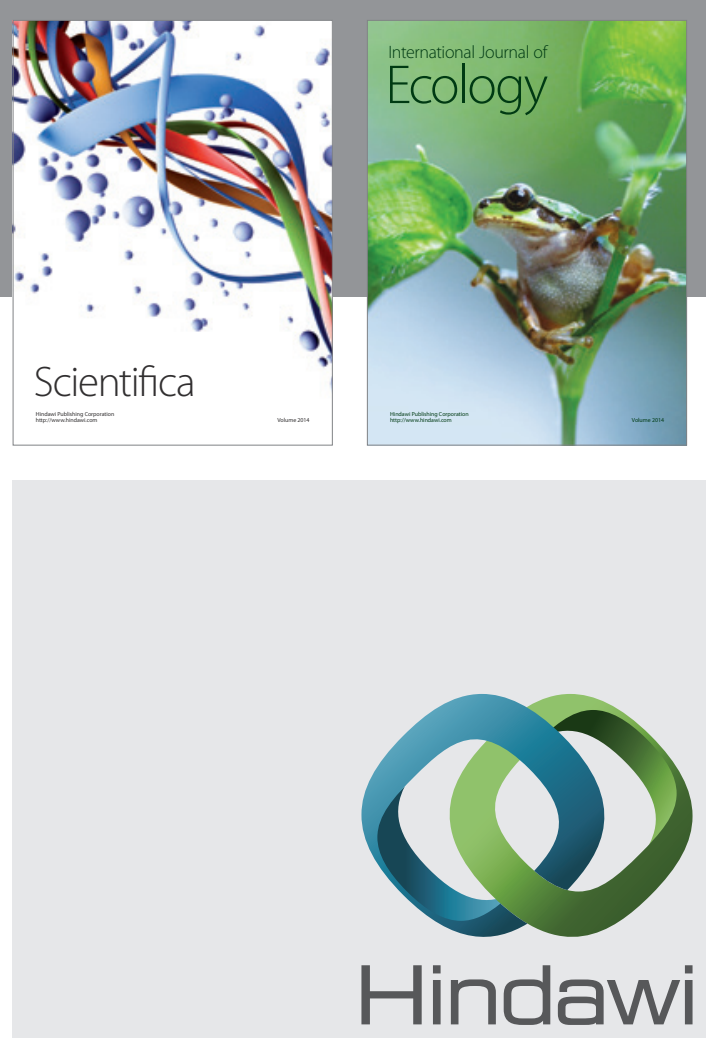

Submit your manuscripts at

http://www.hindawi.com
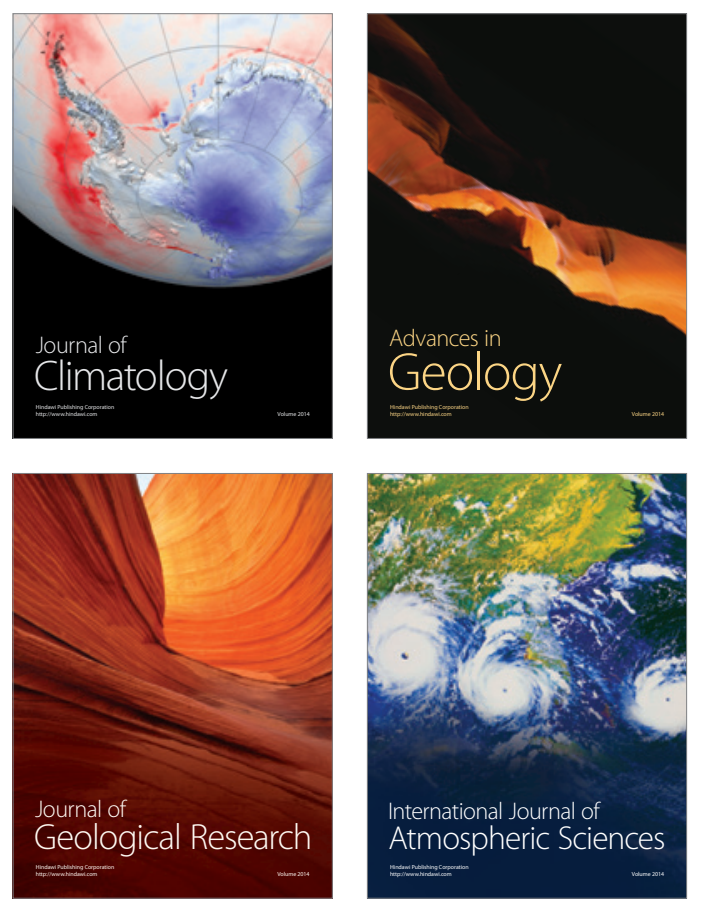

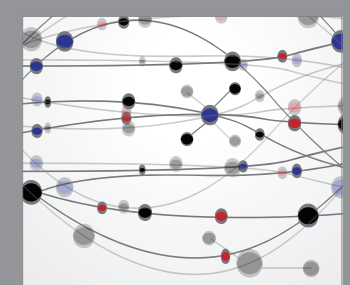

The Scientific

\section{World Journal}
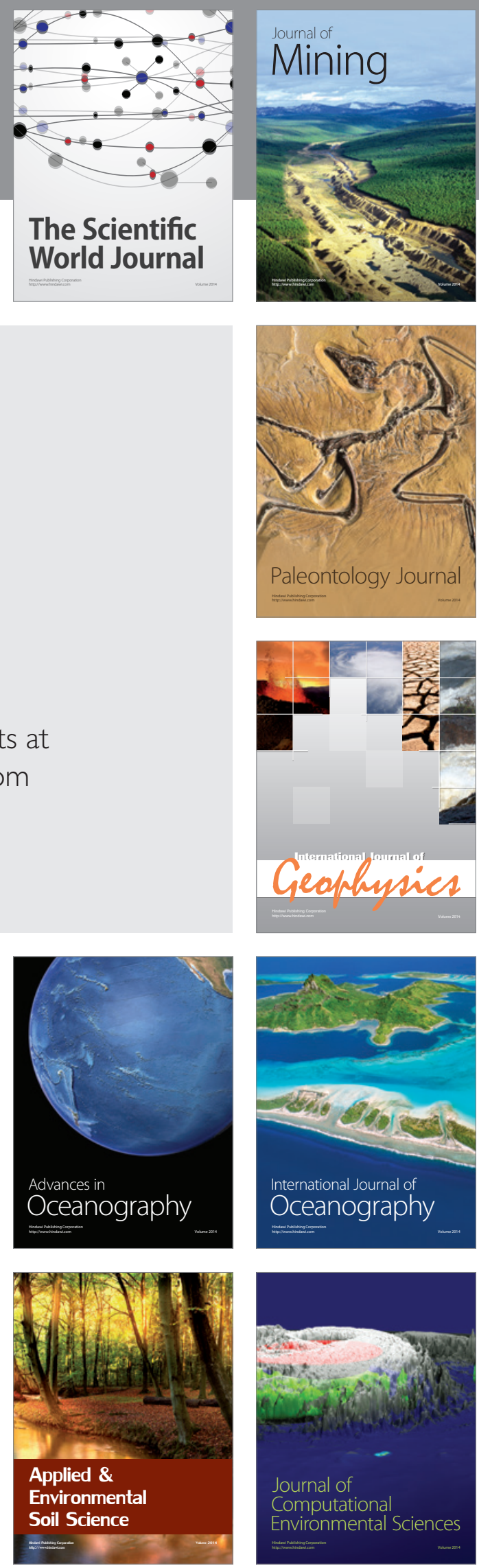